\title{
Multidisciplinary consensus on screening for, diagnosis and management of fetal growth restriction in the Netherlands
}

Viki Verfaille ${ }^{1 *} \mathbb{D}$, Ank de Jonge ${ }^{1}$, Lidwine Mokkink², Myrte Westerneng ${ }^{1}$, Henriëtte van der Horst ${ }^{3}$, Petra Jellema', Arie Franx ${ }^{4}$ and IRIS study group

\begin{abstract}
Background: Screening for, diagnosis and management of intrauterine growth restriction (IUGR) is often performed in multidisciplinary collaboration. However, variation in screening methods, diagnosis and management of IUGR may lead to confusion. In the Netherlands two monodisciplinary guidelines on IUGR do not fully align. To facilitate effective collaboration between different professionals in perinatal care, we undertook a Delphi study with uniform recommendations as our primary result, focusing on issues that are not aligned or for which specifications are lacking in the current guidelines.
\end{abstract}

Methods: We conducted a Delphi study in three rounds. A purposively sampled selection of 56 panellists participated: 27 representing midwife-led care and 29 obstetrician-led care. Consensus was defined as agreement between the professional groups on the same answer and among at least $70 \%$ of the panellists within groups.

Results: Per round 51 or 52 (91\% - 93\%) panellists responded. This has led to consensus on 27 issues, leading to four consensus based recommendations on screening for IUGR in midwife-led care and eight consensus based recommendations on diagnosis and eight on management in obstetrician-led care. The multidisciplinary project group decided on four additional recommendations as no consensus was reached by the panel. No recommendations could be made about induction of labour versus expectant monitoring, nor about the choice for a primary caesarean section.

Conclusions: We reached consensus on recommendations for care for IUGR within a multidisciplinary panel. These will be implemented in a study on the effectiveness and cost-effectiveness of routine third trimester ultrasound for monitoring fetal growth. Research is needed to evaluate the effects of implementation of these recommendations on perinatal outcomes.

Trial registration: NTR4367.

Keywords: Intrauterine growth restriction, fetal growth restriction, Delphi technique, Practice guideline, Prenatal ultrasonography, Collaboration, Uniform approach

\section{Background}

Infants with intrauterine growth restriction (IUGR) are at increased risk for perinatal morbidity and mortality [1-4]. Therefore screening for, diagnosis and management of IUGR are important assignments for all caregivers in perinatal care [5-7].

\footnotetext{
* Correspondence: v.verfaille@vumc.nl

${ }^{1}$ Midwifery Science, AVAG, Amsterdam Public Health research institute, VU University Medical Center, Van der Boechorststraat 7, 1081, BT, Amsterdam, the Netherlands

Full list of author information is available at the end of the article
}

IUGR is defined as the failure to achieve full fetal growth potential. Abdominal palpation or serial fundal height (SFH) measurements are primarily used in clinical practice to assess fetal growth. Additional diagnostic testing by ultrasound biometry is done if indicated, based on relevant history, pregnancy complications or clinical suggestion of IUGR based on abdominal palpation or SFH measurements $[8,9]$. An estimated fetal weight (EFW) below the 10th centile of a population curve is most commonly used in literature and guidelines as a proxy for IUGR [10-14]. If IUGR is 
suspected, additional tests such as Doppler velocimetry can show redistribution patterns of blood flow, suggestive for the fetal adaptive response to suboptimal conditions, either caused by asphyxia or maternal malnutrition [15-19].

Perinatal care for IUGR requires multidisciplinary collaboration, as pregnant women may transit from low- to high-risk care during pregnancy. Consequently uniform multidisciplinary definitions and guidelines are required to reduce inconsistencies in the clinical management of IUGR, a challenge that has been recognised internationally [20-23]. In the Netherlands the guideline of the Royal Dutch Organisation of Midwives (KNOV) focuses on screening in the low-risk population, whereas the guideline of the Dutch Society of Obstetrics and Gynaecology (NVOG) focuses on diagnostics and management when IUGR is already suspected [13, 14]. Unfortunately, there are inconsistencies between these guidelines. For example, the 2008 NVOG guideline only briefly mentions SFH measurements, whereas the 2013 KNOV guideline introduces it as the designated method for monitoring fetal growth [14]. Furthermore, certain aspects of clinical practice such as indications for additional testing are not specified, leaving room for personal interpretation and leading to a wide variation of practice among midwives and among obstetricians.

In the IUGR Risk Selection (IRIS) study the effectiveness and cost-effectiveness of routine third trimester ultrasound for monitoring fetal growth in comparison with usual care will be evaluated in low-risk pregnancies [24]. The outcomes of this study will be affected by the subsequent diagnostics and management of pregnancies with suspected IUGR, requesting a uniform approach by all the professionals involved. However, a lack of consistent scientific evidence leads to wide variations in some clinical practices. We therefore developed uniform multidisciplinary recommendations by carrying out a Delphi study.

The main purpose of the Delphi study reported here was to achieve consensus on issues where evidence is still lacking or where discrepancies were identified on screening for, diagnosis and management of IUGR among professionals in a multidisciplinary care setting.

\section{Methods}

\section{Delphi technique}

We chose a Delphi technique because this allows for consensus among panellists with different backgrounds and possibly conflicting interests, obtained through several rounds of structured questionnaires accompanied by substantive arguments provided by the panel itself. We planned three rounds and asked panellists to respond within three weeks in each round. Non-responders were reminded by personal mailing and eventually a telephone call.
Before the start of data collection we aimed for a panel of at least 50 members and we defined consensus a priori as agreement between the professional groups on the same answer and among at least $70 \%$ of the panellists within groups. The panellists were explicitly informed about this definition of consensus.

\section{Selection of the Delphi panel}

To facilitate multidisciplinary support for the recommendations being developed in this Delphi study, both midwives and obstetricians were recruited throughout the Netherlands using email, telephone and tweets in August and September 2013. We aimed for an equal representation of midwife-led and obstetrician-led care. All potential participants were requested to complete a short questionnaire allowing us to select participants based on their professional expertise and setting. In addition, we personally approached midwives and obstetricians who were involved in the development of the Dutch guidelines for IUGR and researchers on IUGR or fetal monitoring.

Panellists remained anonymous to each other and received no financial or other compensation for their participation.

\section{Preparation of the Delphi questionnaires}

The evidence based, monodisciplinary KNOV and NVOG guidelines were the leading sources for the development of the questionnaires as these are applied in current practice [13, 14]. Furthermore, we used the more recent guideline of the Royal College of Obstetricians and Gynaecologists (RCOG) because it incorporates screening in the general population as well as additional diagnostics and management for the population at risk for IUGR [12]. The British antenatal care also involves multidisciplinary collaboration between midwives or general practitioners in the community and obstetricians. In addition, the RCOG guideline explicitly incorporates SFH measurements plotted on a customised growth chart as recommended in the KNOV guideline [12].

Screening strategies, additional diagnostics and management options were identified in these guidelines (Figure 1). We rephrased the detected inconsistencies and unspecified thresholds for diagnostic tests or interventions in questions. Potential answers were also based on these guidelines or searched for in recent literature.

The project group consisting of all authors approved the content and phrasing of the questions and the response options. For some items, additional advice was asked from an obstetrician and sonographer from the IRIS study group. 


\section{The rounds}

This Delphi study consisted of three rounds of questionnaires, submitted online between September 25th 2013 and January 2nd 2014 (Fig. 1).

The first round focused on screening for IUGR in midwife-led care and on diagnostic tests to be considered in obstetrician-led care if IUGR is suspected. It also incorporated questions about quality of ultrasound biometry as this is mentioned, though not specified, by the KNOV guideline [14]. For each question, the panellists were asked to select their preferred answer or make another suggestion under the response option "other". In every consecutive round, the answers given in the previous round were presented in tables with both absolute numbers and percentages, categorised per professional group. The questionnaire was also accompanied by a feedback report of all explanations for every answer provided by the panellists, offering the panellists the opportunity to reconsider their opinion in relation to the answers of the complete panel.

For example, a question in the first round was: "How should slow growth in SFH measurements be defined?" Panellists were asked to choose between: "by eye-balling", "with a decrease of a specified number of centiles on the customised growth chart (CGC)", "with a combination of both previous methods", "no opinion" or "other". Panellists were encouraged to explain their choices.

Only if no consensus was reached, the question was rephrased in the second round in a statement based upon the given answers and comments (Fig. 1). For example: "Slow growth in SFH measurements should be

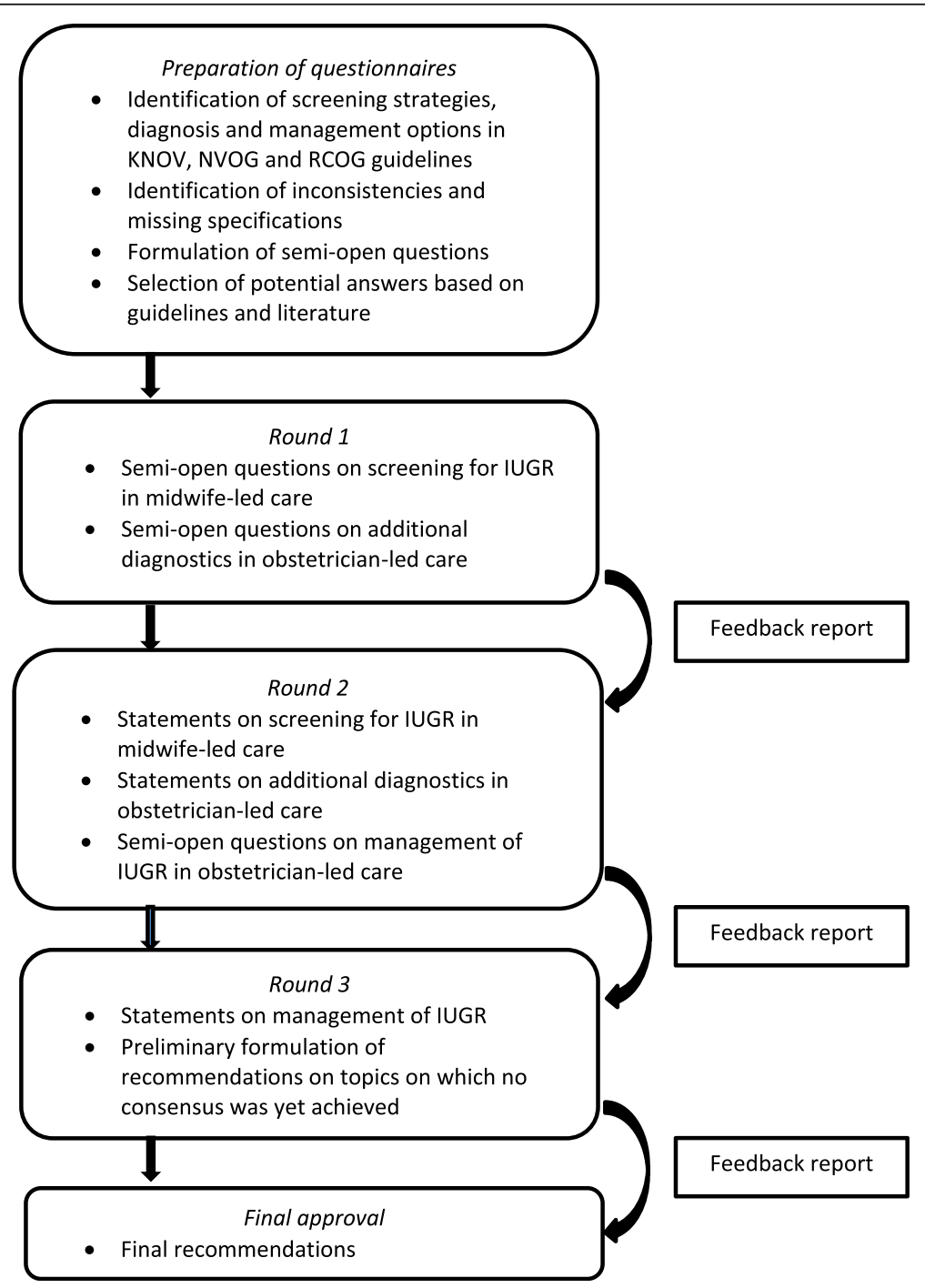

Fig. 1 The Delphi procedure. KNOV = Royal Dutch Organisation of Midwives, NVOG = Dutch Society of Obstetrics and Gynaecology, RCOG = Royal College of Obstetricians and Gynaecologists, IUGR = intrauterine growth restriction 
defined with a decrease of a specified number of centiles on the CGC", as this option was preferred most in round 1. The panellists were asked to rate their (dis)agreement on a Likert scale, including the option "no opinion" so professionals from different disciplines were not forced to decide on specific topics beyond their expertise. For the calculation of the rates of agreement, this option was excluded. Questions about management of IUGR in secondary or tertiary care were added to these statements in the second round.

In the third round we similarly asked the panellists to score statements for which consensus had not been reached, relating them to the recommendations for the IRIS study. In our example: "In the IRIS protocol we will advise to define slow growth in SFH measurements with a decrease of a specified number of centiles on the CGC. Eye-balling is of secondary importance." No new questions were added in this round.

The multidisciplinary project group considered the importance of the statements for which still no consensus was achieved in the final round in the perspective of the IRIS study. For those considered important and possible based on the results of the Delphi procedure, the project group formulated a recommendation for the IRIS study. For all recommendations it was explicitly mentioned whether it was based on a guideline, the Delphi procedure or a decision of the project group. The Delphi panel was asked for a final approval of all the resulting recommendations before the start of the IRIS study.

\section{Results}

In total, 84 professionals responded. From these we selected the panellists warranting an equal representation of midwife-led and obstetrician-led care, experience with SFH measurements and ultrasonography. We also warranted a sample of Dutch regions and tertiary care centres. This led to 56 panellists: 27 representing midwife-led care and 29 obstetrician-led care. Two midwives who solely worked in a hospital were assigned to the obstetrician-led care group. Their characteristics are shown in Table 1.

Figure 2 shows the participation rate (range 91\% to 93\%) per professional group per round. All panellists participated in at least one round, $45(80 \%)$ panellists participated in all three rounds, two (4\%) dropped out after completing the first round in spite of several reminders. The main reason for not participating was lack of time.

\section{Screening}

Table 2 shows the questions and statements concerning screening in midwife-led care for IUGR after 26 weeks gestational age. The Delphi procedure resulted in four consensus based recommendations and one formulated by the project group.

After three rounds, the majority of professionals agreed that slow growth should be defined by a decrease of a specified number of centiles, both for SFH measurements as for ultrasound biometry, rather than through eye-balling alone (statements 1.1 and 1.3). In the first round, panellists who considered the specification of a number of centiles necessary for defining slow growth in SFH measurements, suggested to use at least 2,10 or 20 centiles as cut-off points. In the second round, consensus was achieved about using a minimum decrease of 20 centiles; no other options had been added by the panellists (statement 1.2).

For EFW based on ultrasound, a decrease of at least 15 or 20 centiles was suggested in the first round, leading to consensus in the second round on a decrease of 20 centiles as the appropriate threshold for referral to obstetrician-led care (statement 1.4). The panel suggested that the same sonographer should perform the consecutive biometry ultrasounds (statement 1.5).

Although there is no compulsory audit for ultrasound biometry in the Netherlands, the majority of panellists agreed upon several quality norms as shown in Table 2. For the sonographers the following consensus was reached: being trained for the 18-23 weeks fetal anomaly scan, repeated education by participating in a training at least once a year, performance of at least 100 biometry scans a year and the yearly evaluation of a $\log$ (describing all exceptional findings) (statements 1.6-1.9). For the ultrasound machine it was agreed that it should meet the high standard as stated for the 18-23 weeks fetal anomaly scan [25] (statement 1.10). No consensus was achieved for the specification of the cut-off value for decreased amniotic fluid volume (statement 1.11). The project group made the recommendation to refer pregnant women to obstetrician-led care if the single deepest vertical pocket is below $2 \mathrm{~cm}$.

\section{Diagnosis}

Table 3 presents the questions and statements about additional diagnostics in obstetrician-led care after referral for IUGR after 26 weeks gestational age. The Delphi technique has led to eight consensus based recommendations and one formulated by the project group.

In the first round several panellists suggested to use the same threshold for decreased amniotic fluid volume for referral to secondary care as for a change in management of pregnancy if already referred. This was rephrased in a statement, reaching consensus in the second round (statement 2.3).

The panellists agreed that when IUGR is suspected at a gestational age of at least 26 weeks, a pulsatility 
Table 1 Characteristics of the Delphi panel

\begin{tabular}{|c|c|c|c|c|c|}
\hline \multirow[t]{3}{*}{ Characteristic } & \multirow{3}{*}{$\begin{array}{l}\text { Midwife-led Care Panellist } \\
N=27(48 \%)\end{array}$} & \multicolumn{3}{|c|}{ Obstetrician-led Care Panellist } & \multirow{3}{*}{$\begin{array}{l}\text { Total group } \\
N=56(100 \%)\end{array}$} \\
\hline & & \multicolumn{3}{|c|}{$N=29(52 \%)$} & \\
\hline & & Secondary care & Tertiary care & Combined & \\
\hline Years of experience in current position, mean (range) & $16.30(3-39)$ & & $12.32(1-40)$ & & $14.97(1-40)$ \\
\hline Midwife & $11(19.6 \%)$ & & & & $11(19.6 \%)$ \\
\hline + sonographer & $12(21.4 \%)$ & 0 & $1(1.8 \%)$ & $1(1.8 \%)$ & $14(25.0 \%)$ \\
\hline + policy and guideline development & $4(7.1 \%)$ & & & & $4(7.1 \%)$ \\
\hline Obstetrician & & $11(19.6 \%)$ & $5(8.9 \%)$ & $1(1.8 \%)$ & $17(30.4 \%)$ \\
\hline+ perinatologist & & $2(3.6 \%)$ & $2(3.6 \%)$ & $1(1.8 \%)$ & $5(8.9 \%)$ \\
\hline + policy \& guideline development and perinatologist & & $1(1.8 \%)$ & $3(5.4 \%)$ & 0 & $4(7.1 \%)$ \\
\hline Expert sonographer & & 0 & $1(1.8 \%)$ & 0 & $1(1.8 \%)$ \\
\hline \multicolumn{6}{|l|}{ Work address } \\
\hline Drenthe & 0 & & 0 & & 0 \\
\hline Flevoland & 0 & & 0 & & 0 \\
\hline Friesland & $2(3.6 \%)$ & & 0 & & $2(3.6 \%)$ \\
\hline Gelderland & $4(7.1 \%)$ & & $2(3.6 \%)$ & & $6(10.7 \%)$ \\
\hline Groningen & 0 & & $1(1.8 \%)$ & & $1(1.8 \%)$ \\
\hline Limburg & $2(3.6 \%)$ & & $2(3.6 \%)$ & & $4(7.1 \%)$ \\
\hline North Brabant & $4(7.1 \%)$ & & $3(5.4 \%)$ & & $7(12.5 \%)$ \\
\hline North Holland & $3(5.4 \%)$ & & 11 (19.6\%) & & $14(25.0 \%)$ \\
\hline Overijssel & $1(1.8 \%)$ & & $1(1.8 \%)$ & & $2(3.6 \%)$ \\
\hline South Holland & $4(7.1 \%)$ & & $5(8.9 \%)$ & & $9(16.1 \%)$ \\
\hline Utrecht & $6(10.7 \%)$ & & $4(7.1 \%)$ & & 10 (17.9\%) \\
\hline Zeeland & $1(1.8 \%)$ & & 0 & & $1(1.8 \%)$ \\
\hline
\end{tabular}

Percentages do not always add up to $100 \%$ due to rounding error

index (PI) of the umbilical artery Doppler of at least the 95th centile would be a first sign for the placental blood supply not meeting the fetal demand, necessitating a change in monitoring and/or management (statements 2.4-2.5). This consensus was achieved after considering measuring the resistance index, additional checking for absent or reversed diastolic flow and other options. Consecutively, based on the answers, the 90th and 95th centile of the PI have been considered as thresholds for changing the monitoring or management of pregnancy. In addition to the umbilical artery Doppler, panellists agreed on the measurement of the PI of the middle cerebral artery Doppler (statement 2.6). No consensus was achieved on the measurement of the ductus venosus Doppler in this case (statement 2.7). Some panellists explained that results of the Trial of Umbilical and Fetal Flow in Europe were soon to be expected and therefore should be waited for to decide about the ductus venosus Doppler [26]. The project group complied with this: no recommendation was made.

For pregnant women without a fetal anomaly scan, the panellists agreed to recommend one if IUGR is suspected (statement 2.8). However, agreement about the indication specified in the degree of IUGR; or who should perform this ultrasound was not achieved (statements 2.9-2.10). The project group has recommended to offer an advanced anomaly scan starting from an EFW of P2.3 or below.

Consensus was achieved that cardiotocography (CTG) monitoring is not indicated in case of suspicion of IUGR as long as there is no decrease in fetal movements, nor a hypertensive disorder and no abnormal Dopplers (statement 2.11).

Gestational age was not regarded an important factor in deciding to check for infections (statement 2.13). Although the degree of IUGR was considered relevant to this decision, no consensus was reached on the threshold for the EFW centile (statement 2.12). Therefore the project group has recommended an EFW at P2.3 or below as the appropriate cut-off point. Toxoplasmosis, Cytomegalovirus and Parvo B19 are infections to be tested for, but not Coxsackie Virus and Malaria. The panel did not reach consensus upon testing for Rubella, Herpes and Syphilis (statement 2.14). 
- Recruitment through e-mail advertising, telephone calls, personal invitations and twitter

- Request for information about professional expertise

84 professionals agreed to participate

56 panellists purposively selected:

27 from midwife-led care

29 from obstetrician-led care

Round 1: 52 panellists responded (93\%)

27 from midwife-led care

25 from obstetrician-led care

Round 2: 51 panellists responded (91\%)

25 from midwife-led care

26 from obstetrician-led care

Round 3: 51 panellists responded (91\%)

23 from midwife-led care

28 from obstetrician-led care

Fig. 2 Flowchart of participation per Delphi round

\section{Management}

Questions and statements about further management of IUGR pregnancies in obstetrician-led care are shown in Table 4. The Delphi procedure has led to eight consensus based recommendations and two formulated by the project group. Consensus was reached that if the EFW is below the fifth centile, the pregnant woman should remain in obstetrician-led care with ultrasound biometry repeated every two weeks (statement 3.1 and 3.3). Disagreement remained whether a pregnancy with an EFW between the fifth and tenth centile and no abnormal results from additional testing, should be monitored in midwife-led care with serial ultrasounds or in obstetrician-led care (statement 3.2). No further recommendation was made by the project group leaving the decision up to the individual professional involved. Additional monitoring of IUGR by the assessment of the amniotic fluid volume and Doppler velocimetry was agreed, however no consensus was achieved on its frequency (statements 3.4- 3.5). The project group advised a repetition of at least every two weeks in combination with the biometry.

Because of the variation in responses on when to refer to tertiary care, we did not reach the stage of formulating statements. The project group has decided to recommend that if there is a reasonable chance of a (necessary) birth before 32 weeks of gestation and/or if the EFW is below $1250 \mathrm{~g}$, the woman should be referred to tertiary care, in accordance to the NVOG guideline.

Also the questions about when induction of labour or a primary caesarean section was indicated never reached the stage of formulating statements, even though the statements concerned IUGR without further abnormalities in additional diagnostics or monitoring. In the third round we tried to narrow it down by suggesting to combine gestational age with degree of IUGR defined as a centile for EFW and/or abdominal circumference. Nevertheless, no uniformity could be detected in the given answers regardless of professional group, refraining the project group from formulating a recommendation.

\section{Discussion}

\section{Summary of the main findings}

In this Delphi study consensus was achieved between professionals working in midwife-led and obstetricianled care on 27 statements, resulting in twenty recommendations for prenatal care for IUGR; this may contribute to optimizing the multidisciplinary teamwork throughout all levels of perinatal care. Consensus was not reached on some statements that were important for the IRIS study, therefore the multidisciplinary project group formulated four recommendations. No recommendations could be made about when to induce labour in absence of further abnormalities in additional diagnostics or monitoring, nor about when to perform a primary caesarean section.

\section{Comparison with other studies or literature}

Consensus was reached on the definition of slow growth as a decrease of 20 centiles in both SFH and EFW measurements plotted on the CGC with a minimum interval of two weeks. As far as we know, this is the first specification of slow growth reported in the literature. Guidelines that mention slow growth do not define it or only generally describe it as a crossing of centiles in a downward direction $[10-12,14]$. The Fetal Growth Longitudinal Study of the Intergrowth-21st Project has recommended international growth standards based on fetal ultrasound measurements: 


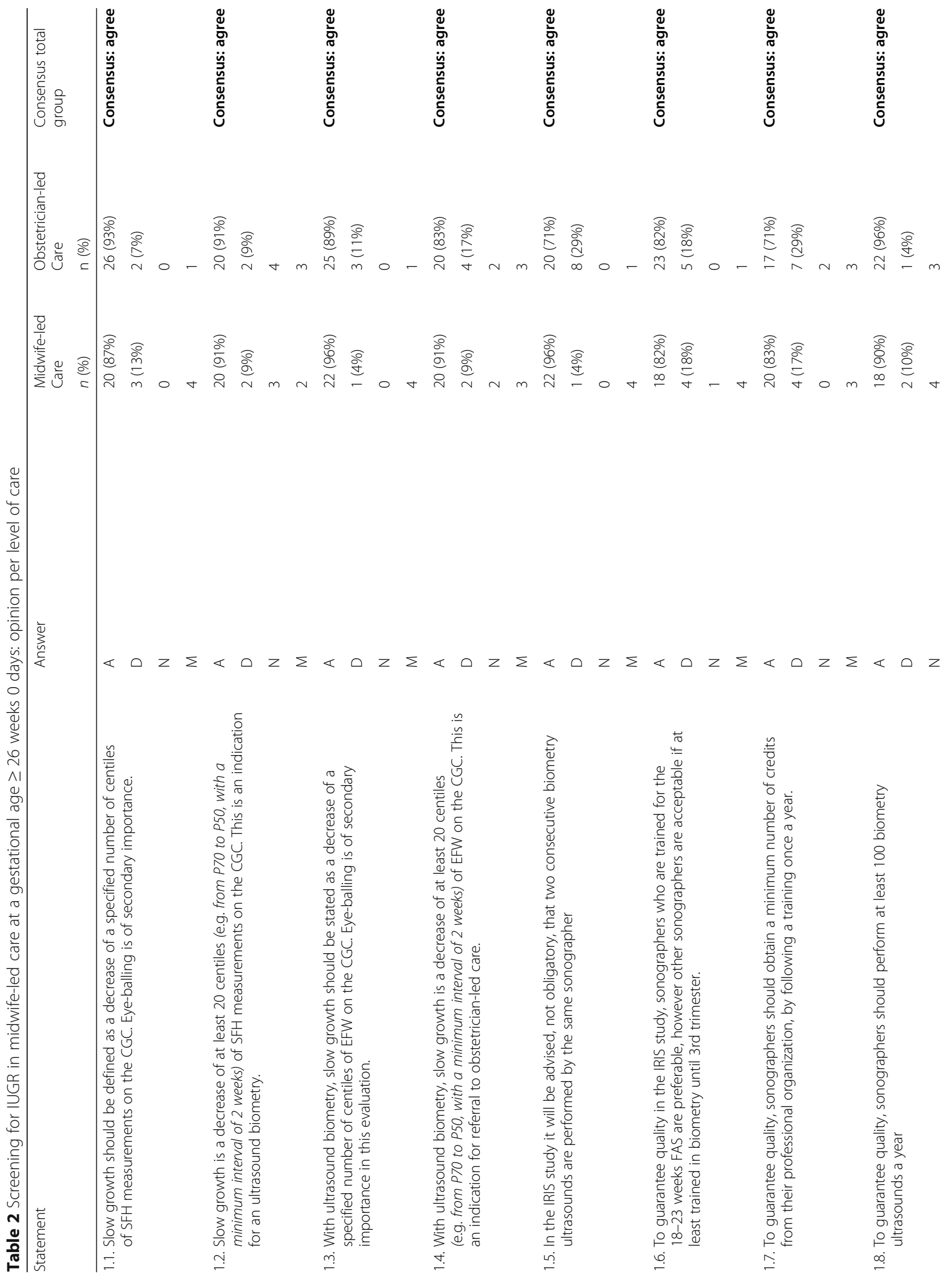




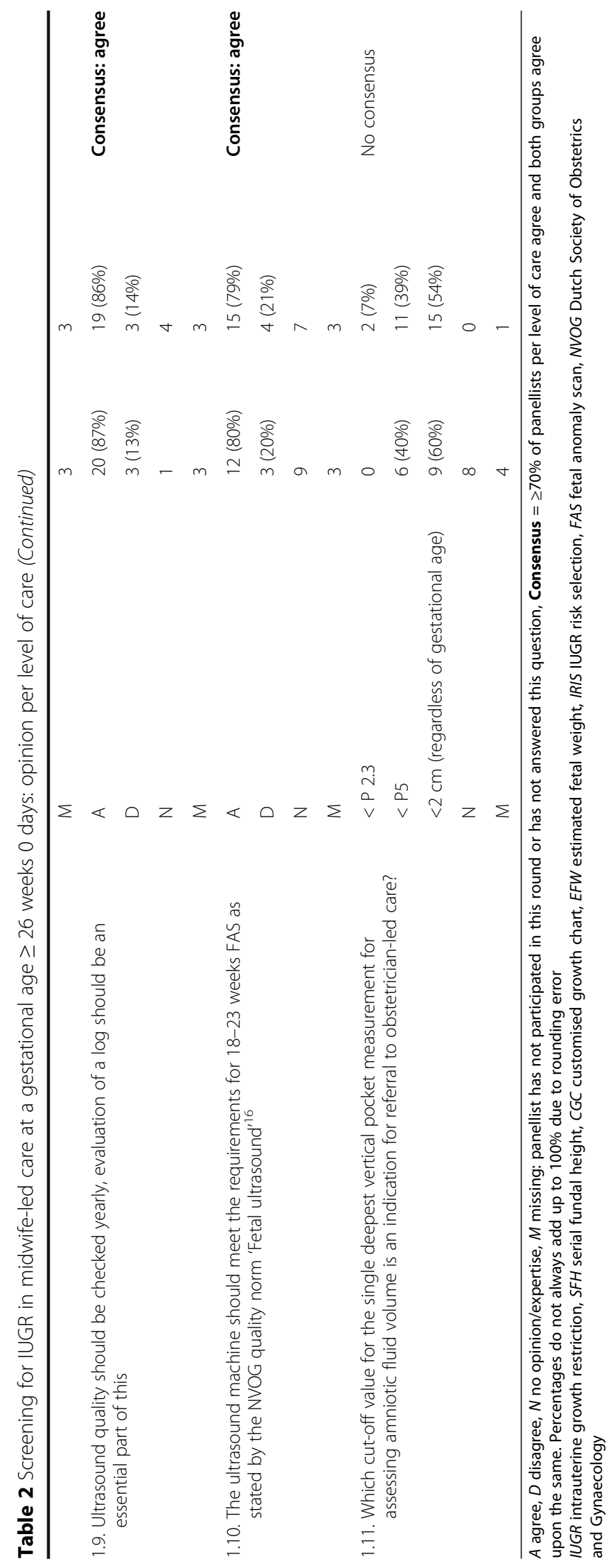




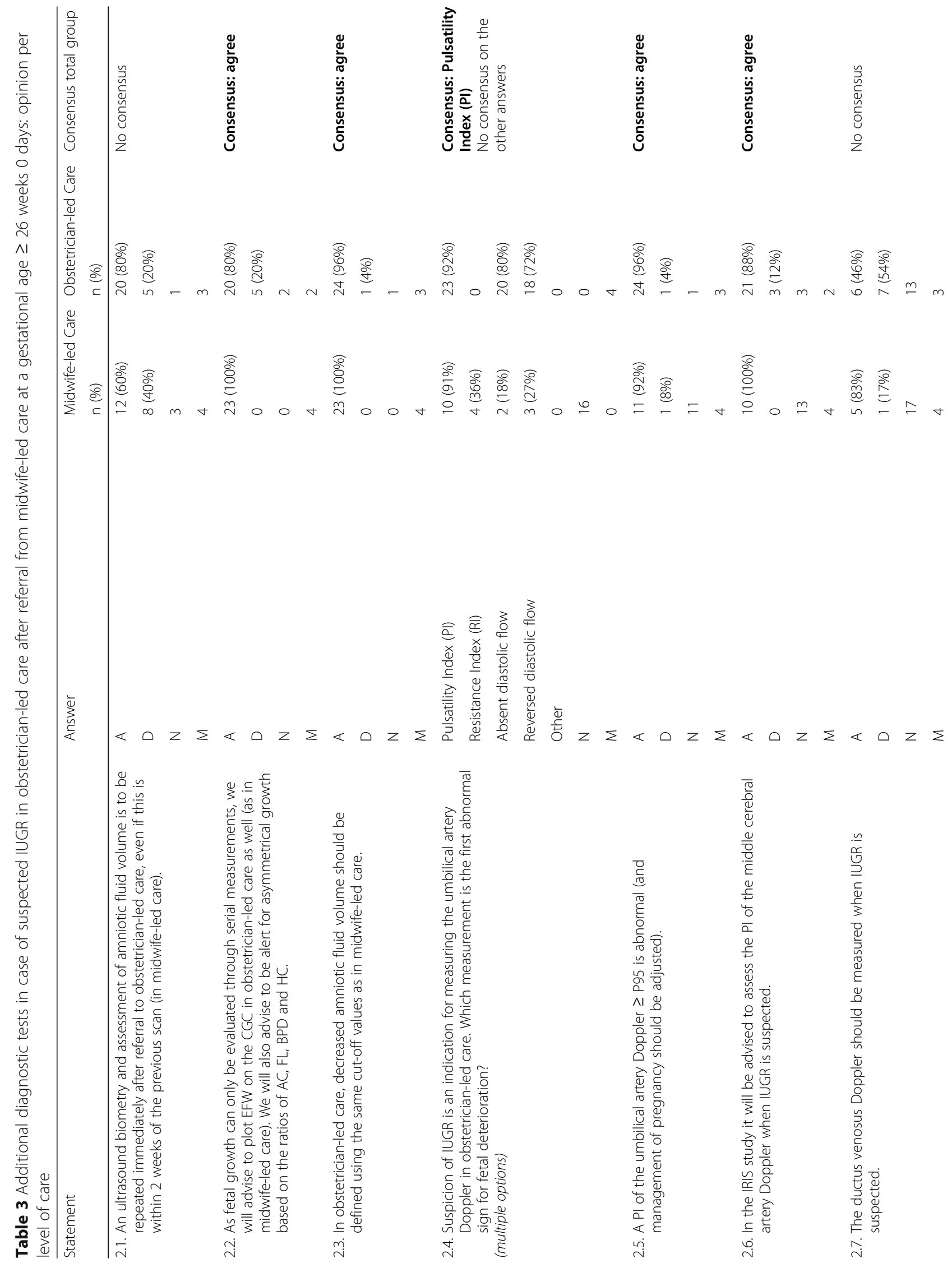




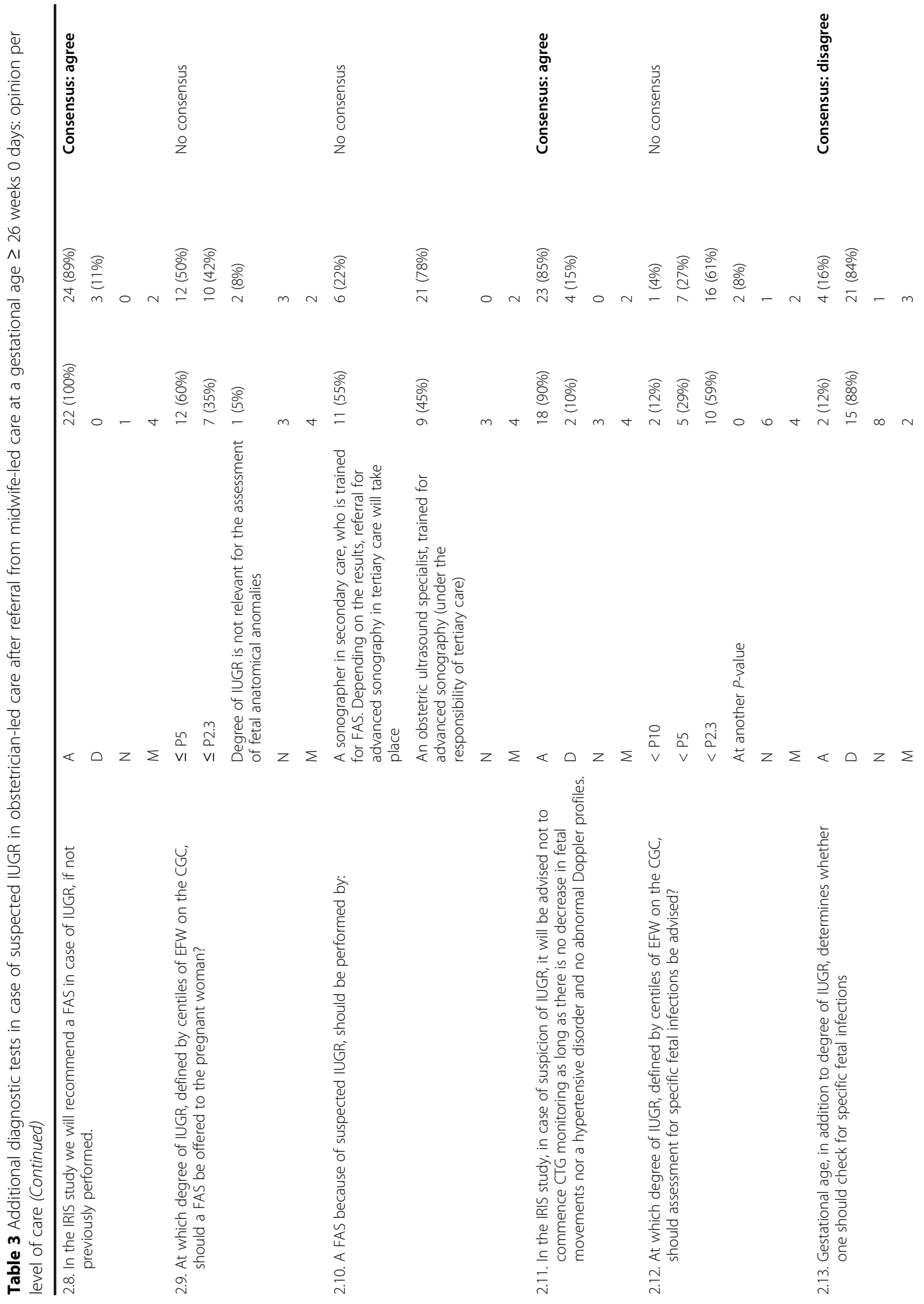




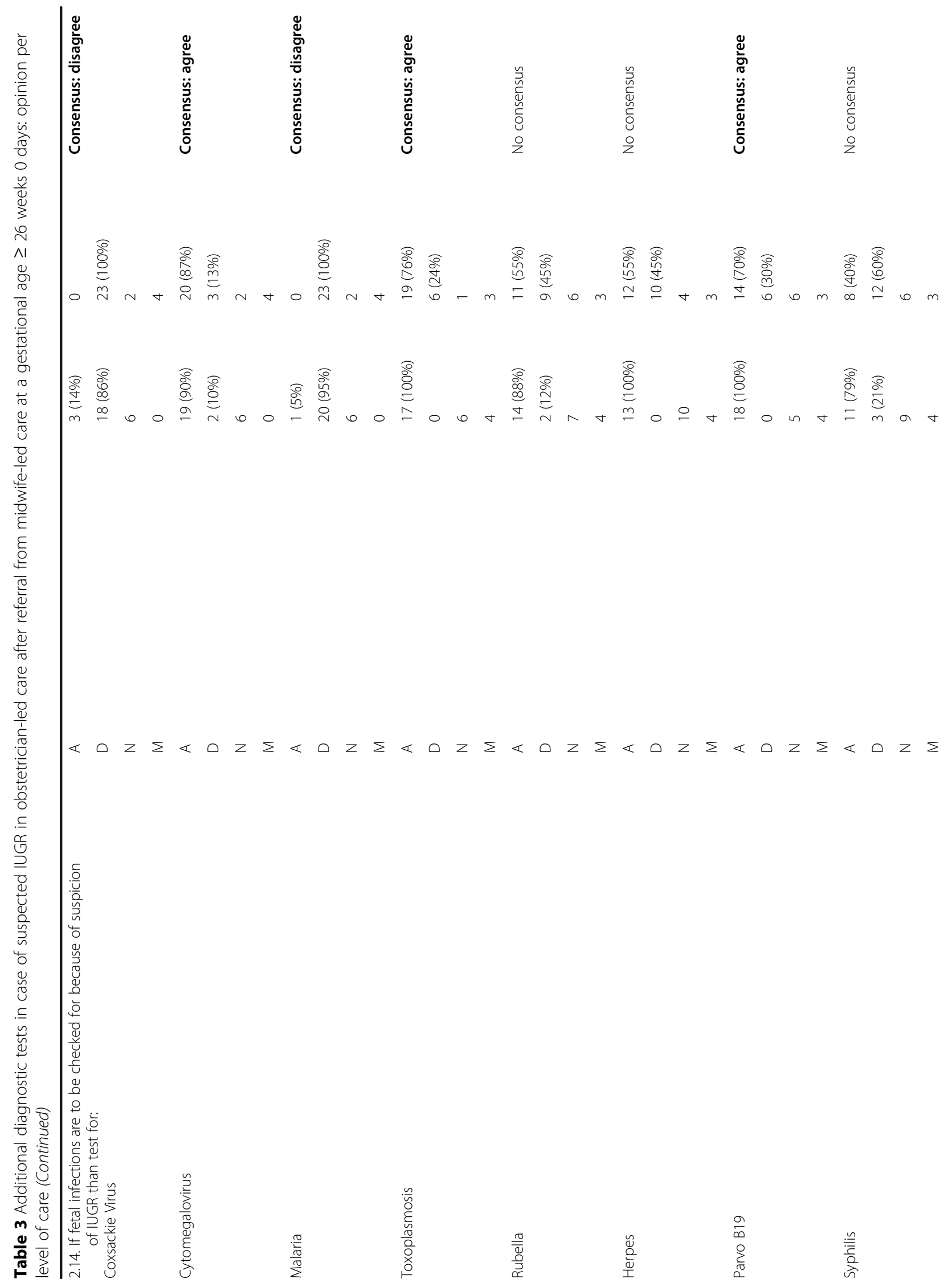




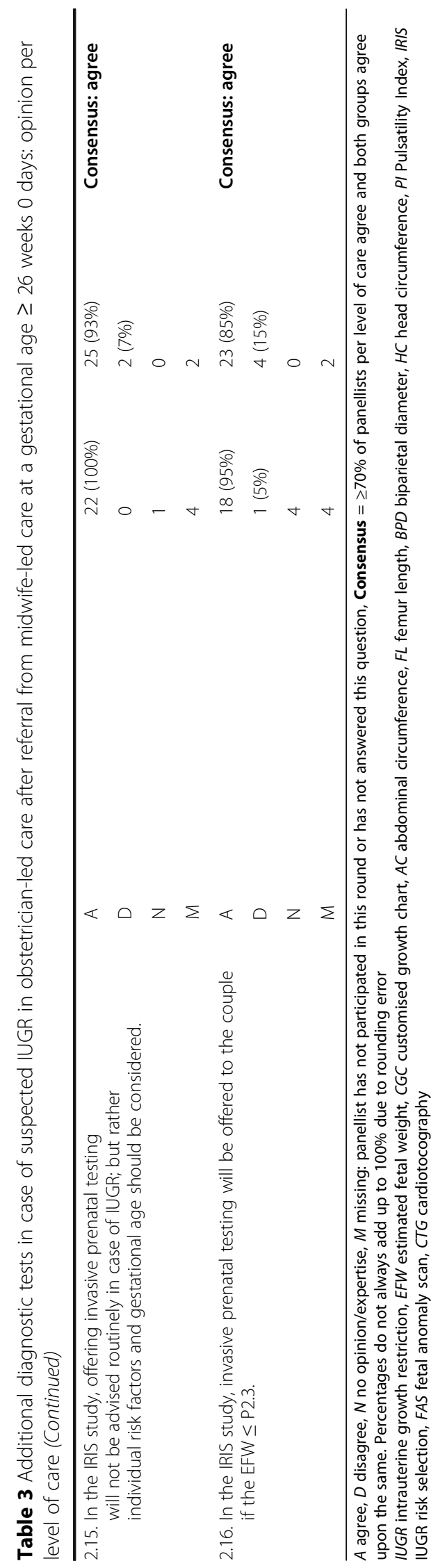




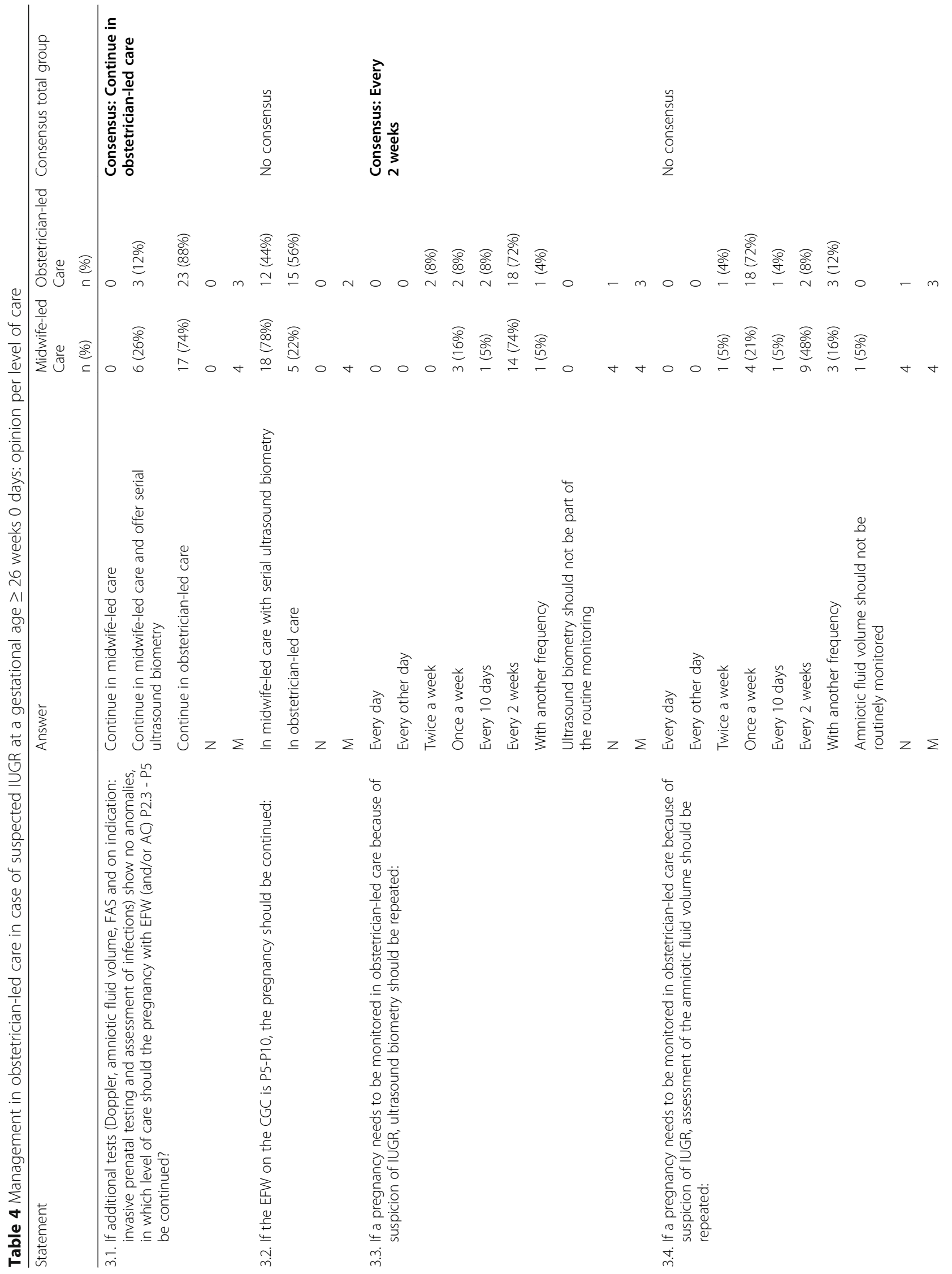




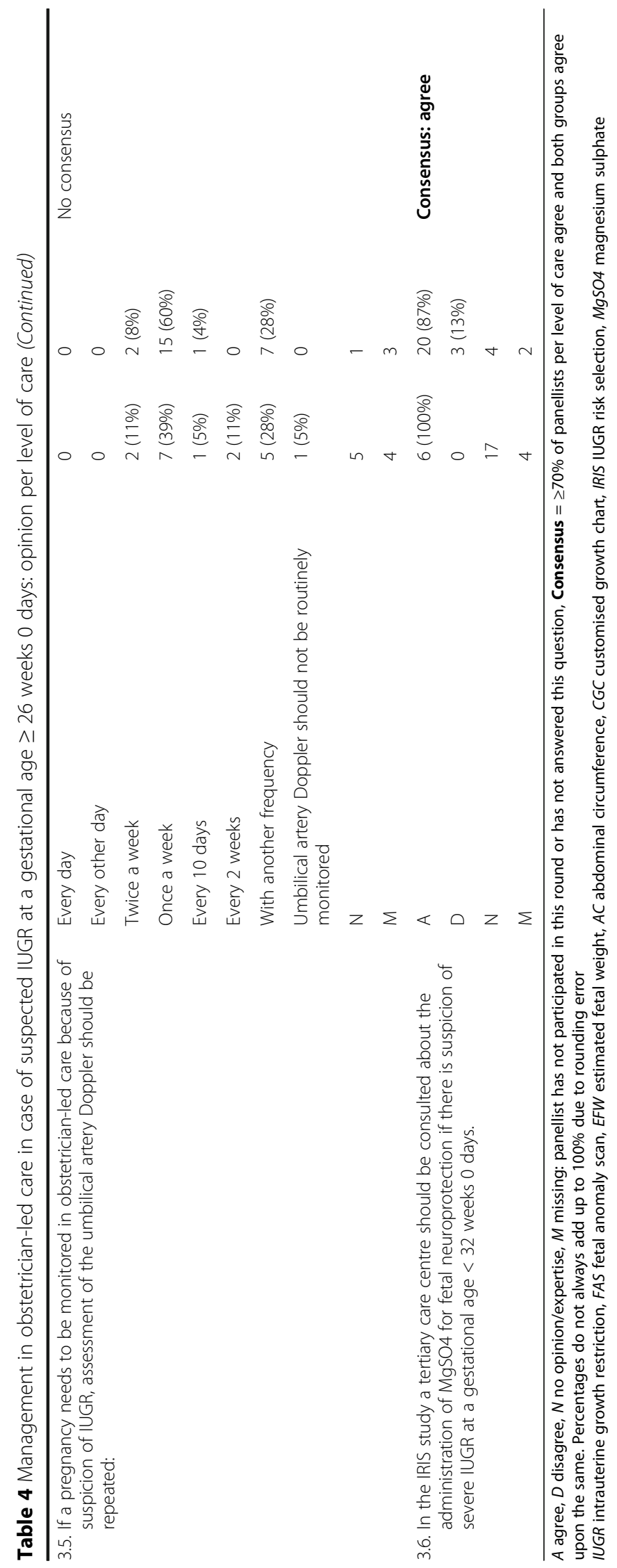


head and abdominal circumference, biparietal diameter, occipitofrontal diameter and femur length [21]. However, they do not define slow growth [21]. Further research is needed to investigate whether this criterion for slow growth is associated with an increased risk of adverse perinatal outcome.

The panellists achieved consensus on quality norms for fetal biometry ultrasounds. Multiple national and international societies have established guidelines and audit systems for assessing the quality of the nuchal translucency scan or the 18-23 weeks fetal anomaly scan $[25,27,28]$. Although recommended in the literature, no audit system for the quality of biometry exists on a national or international level [29-33]. This is surprising considering the role of biometry in diagnosing and managing IUGR [1-5]. In this Delphi study consensus was reached for requirements for both the ultrasound machine and the sonographer. This could offer a basis for the development of quality audits and certification in biometry. Further research is needed to consider these requirements from an educational or quality assessment perspective, as the panellists were primarily selected for their expertise on IUGR rather than on education or quality assessment.

Doppler velocimetry can be used to monitor redistribution patterns of blood flow in the pregnancy with IUGR, suggesting a risk for further fetal compromise [15, 17, 34]. However, besides assessment of the umbilical artery in the third trimester of pregnancy, Doppler measurements of various other vessels are suggested in guidelines, without specification of thresholds [10-13, 35]. In this Delphi study the panel specified abnormal flow as an umbilical artery PI of $95 \%$ and above. In addition, the measurement of the middle cerebral artery Doppler PI was considered to contribute to the surveillance in case of IUGR, but the threshold for abnormal flow was not specified.

Unlike the American Congress of Obstetricians and Gynecologists (ACOG) guideline, but in line with the RCOG and the Society of Obstetricians and Gynaecologists of Canada (SOGC) guideline, the panel agreed not to advise CTG monitoring for IUGR, as long as other measurements such as Doppler velocimetry remain normal and without a decrease of fetal movements or hypertensive disorders [10-12].

No recommendations were made about induction of labour versus expectant monitoring based on the combination of gestational age and degree of IUGR in absence of further abnormalities in additional tests. The panellists, regardless of their professional group, indicated various things and thresholds to consider for each pregnancy individually. The RCOG guideline recommends a senior obstetrician to determine the timing and mode of birth in pregnancies with a small-for-gestational-age fetus detected after 32 weeks with normal umbilical artery Doppler. Furthermore they recommend that delivery should be offered at 37 weeks of gestation [12]. In the Disproportionate Intrauterine Growth Intervention Trial At Term, no important differences in adverse outcomes were found between both strategies [36, 37]. The project group also left the decision up to the obstetrician involved as support for a general recommendation was lacking.

\section{Strengths and limitations}

A strength of the study is that we could select a panel of 56 members from 84 candidates, equally representing professionals from midwife-led and obstetrician-led care from a wide range of the Dutch geographical areas. Although there is no uniform recommendation about the size of a Delphi panel, we exceeded our predefined number of 50 which seems fair compared to other studies [38]. We deem expertise on IUGR to be properly represented in this Delphi panel, therefore, content validity of the results may be assumed [39]. The response rate of $91-93 \%$ of panellists per round was high, exceeding the recommendation of $70 \%$ per round suggested by others $[40,41]$.

Implementation of and adherence to guidelines for clinical practice is known to be complex [42-44]. Through the active involvement of this multidisciplinary panel from all over the country we aim to improve bottom up support for the recommendations in the IRIS study. This may lead to perceptions of ownership and acceptance of more uniform recommendations, which in turn might increase implementation in daily practice $[43,45]$.

While there is no general rule about how consensus should be defined in a Delphi study, levels starting from $51 \%$ agreement have been described $[38,46]$. Compared to this our criterion stated a priori of at least $70 \%$ seems reasonable and suggests enough support in daily practice for the emerging recommendations. Furthermore, this percentage is a means to stimulate achieving consensus among the majority of professionals involved rather than a goal in itself. As we did not count the answer "no opinion" for the rate of agreement, it was possible to effectively use the panellists with expertise on the concerning topic. Panellists often explained they had no expertise concerning the particular subject if they chose this option. For example, a primary care midwife was not obliged to (dis)agree about when magnesium sulphate should be administered, as this is no part of her training nor her discipline.

\section{Conclusions}

In this study we achieved consensus within a multidisciplinary panel on 27 statements about prenatal care for IUGR. This has led to twenty consensus based recommendations that will be implemented in a study on the effectiveness and cost-effectiveness of routine third trimester ultrasound for monitoring fetal growth. 


\section{Abbreviations}

AC: Abdominal circumference; BPD: Biparietal diameter; CGC: Customised growth chart; CTG: Cardiotocography; EFW: Estimated fetal weight; FAS: Fetal anomaly scan; FL: Femur length; HC: Head circumference; IRIS study: IUGR risk selection study; IUGR: Intrauterine growth restriction; KNOV: Royal Dutch Organisation of Midwives; MgSO4: Magnesium sulphate; NVOG: Dutch Society of Obstetrics and Gynaecology; PI: Pulsatility Index; RCOG: Royal College of Obstetricians and Gynaecologists; SFH: Serial fundal height

\section{Acknowledgements}

We are grateful to all the members of the Delphi panel for the effort and time they invested in this study. Group authorship: The IRIS study group.

Joke Bais; Gouke J. Bonsel; Judith E. Bosmans; Jeroen van Dillen; Noortje T.L. van Duijnhoven; William A. Grobman; Henk Groen; Chantal W.P.M. Hukkelhoven; Trudy Klomp; Marjolein Kok; Marlou L. de Kroon; Maya Kruijt; Anneke Kwee; Sabina Ledda; Harry N. Lafeber; Jan M. van Lith; Ben Willem Mol; Bert Molewijk; Marianne Nieuwenhuijze; Guid Oei; Cees Oudejans; K. Marieke Paarlberg; Eva Pajkrt; Aris T. Papageorghiou; Uma M. Reddy; Paul A.O.M. De Reu; Marlies Rijnders; Alieke de Roon-Immerzeel; Connie Scheele; Sicco A. Scherjon; Rosalinde Snijders; Pim W. Teunissen; Hanneke W. Torij; Jos Twisk; Kristel C. Zeeman; Jun Zhang.

\section{Funding}

The IRIS study received funding from the Netherlands Organization for Health Research and Development (ZonMw) in the context of the research program Pregnancy and Childbirth, grant number: 209,030,001. ZonMw was not involved in the design of the study and collection, analysis, and interpretation of data and in writing this manuscript.

\section{Availability of data and materials}

The data on which the recommendations are based are published in this article in Tables 2, 3 and 4. Raw data, analysed during this Delphi study are not publicly available as they are written in Dutch, but are available from the corresponding author on reasonable request.

\section{Authors' contributions}

AdJ, LM, HvdH, PJ and AF were involved in study conception and design. W, AdJ, LM and PJ were involved in the development and/or implementation of the study. W and MW acquired the data. W, PJ and AdJ interpreted the data and were involved in drafting the manuscript. All authors critically read and approved the final manuscript and agreed to be accountable for all aspects of the work presented in this manuscript.

\section{Ethical considerations and consent to participate}

The design and planning of the Delphi study were presented to the Dutch Institutional Review Board (METC) of the VU Medical University Centre Amsterdam as a part of the IRIS study. The Board confirmed that an official ethical approval of this study is not required. Participants consented by volunteering to participate in the Delphi study.

\section{Consent for publication}

Not applicable.

\section{Competing interests}

The authors declare that they have no competing interests.

\section{Publisher's Note}

Springer Nature remains neutral with regard to jurisdictional claims in published maps and institutional affiliations.

\footnotetext{
Author details

${ }^{1}$ Midwifery Science, AVAG, Amsterdam Public Health research institute, VU University Medical Center, Van der Boechorststraat 7, 1081, BT, Amsterdam, the Netherlands. ${ }^{2}$ Department of Epidemiology and Biostatistics and Amsterdam Public Health research institute, VU University Medical Center, Van der Boechorststraat 7, 1081, BT, Amsterdam, the Netherlands. ${ }^{3}$ Department of General Practice, Amsterdam Public Health research institute, VU University Medical Center, Van der Boechorststraat 7, 1081, BT, Amsterdam, the Netherlands. ${ }^{4}$ Department of Gynecology, Utrecht University Medical Centre, Heidelberglaan 100, 3584, CX, Utrecht, the Netherlands.
}

Received: 11 July 2016 Accepted: 15 September 2017

Published online: 16 October 2017

\section{References}

1. Boulet SL, Alexander GR, Salihu HM, Kirby RS, Carlo WA. Fetal growth risk curves: defining levels of fetal growth restriction by neonatal death risk. Am J Obstet Gynecol. 2006;195(6):1571-7.

2. De Reu PA, Oosterbaan HP, Smits L, Nijhuis JG. Avoidable mortality in small-for-gestational-age children in the Netherlands. J Perinat Med. 2010;38(3):311-8.

3. Flenady V, Koopmans L, Middleton P, Froen JF, Smith GC, Gibbons K, et al. Major risk factors for stillbirth in high-income countries: a systematic review and meta-analysis. Lancet. 2011;377(9774):1331-40.

4. Gardosi J, Kady SM, McGeown P, Francis A, Tonks A. Classification of stillbirth by relevant condition at death (ReCoDe): population based cohort study. BMJ. 2005;331(7525):1113-7.

5. Darmstadt GL, Shiffman J, Lawn JE. Advancing the newborn and stillbirth global agenda: priorities for the next decade. Arch Dis Child. 2015;100(Suppl 1):S13-8.

6. Beamish N, Francis A, Gardosi J. Intrauterine growth restriction as a risk factor for infant mortality. Arch Dis Child Fetal Neonatal Ed. 2008;93

7. Lindqvist PG, Molin J. Does antenatal identification of small-for-gestational age fetuses significantly improve their outcome? Ultrasound Obstet Gynecol. 2005;25(3):258-64.

8. American College of Obstetricians and Gynecologists. ACOG Practice Bulletin No. 101: Ultrasonography in pregnancy. Obstet Gynecol. 2009;113(2 Pt 1):451.

9. NICE NCCFWaCH. NICE guideline: antenatal care. London: Royal College of Obstetricians and Gynaecologists Press; 2008. https://www.nice.org.uk/ guidance/cg62. Accessed 7 Aug 2014

10. Chauhan SP, Gupta LM, Hendrix NW, Berghella V. Intrauterine growth restriction: comparison of American College of Obstetricians and Gynecologists practice bulletin with other national guidelines. Am J Obstet Gynecol. 2009:200(4):409-6.

11. Lausman A, Kingdom J, Gagnon R, Basso M, Bos H, Crane J, et al. Intrauterine growth restriction: screening, diagnosis, and management. J Obstet Gynaecol Can. 2013;35(8):741-57.

12. Guidelines Committee of the Royal College of Obstetricians and Gynaecologists. The Investigation and Management of the Small-forGestational-Age Fetus RCOG Green-top Guideline No.31. Birmingham: RCOG; 2013. https://www.rcog.org.uk/en/guidelines-research-services/ guidelines/gtg31/. Accessed 15 Jul 2013.

13. Nederlandse Vereniging voor Obstetrie \& Gynaecologie. Foetale groeibeperking Versie 2.1 NVOG richtlijn: NVOG, Utrecht; 2008. http://nvogdocumenten.nl/index.php?pagina=/richtlijn/item/pagina.php\&richtlijn_id= 828. Accessed 15 Jul 2013.

14. Beentjes M, de Roon-Immerzeel A, Zeeman K. Opsporing van foetale groeivertraging KNOV-standaard. Utrecht: Koninklijke Nederlandse Organisatie van Verloskundigen; 2013. https://www.knov.nl/vakkennis-enwetenschap/tekstpagina/263-3/opsporing-foetale-foetalegroeivertraging/ hoofdstuk/283/opsporing-foetale-groeivertraging/. Accessed 15 Jul 2013.

15. Morris RK, Malin G, Robson SC, Kleijnen J, Zamora J, Khan KS. Fetal umbilical artery Doppler to predict compromise of fetal/neonatal wellbeing in a highrisk population: systematic review and bivariate meta-analysis. Ultrasound Obstet Gynecol. 2011;37(2):135-42.

16. Alfirevic Z, Stampalija T, Gyte GM. Fetal and umbilical Doppler ultrasound in normal pregnancy (Review). Cochrane Database Syst Rev. 2010;8:1-83.

17. Alfirevic Z, Stampalija T, Gyte GM. Fetal and umbilical Doppler ultrasound in high-risk pregnancies (Review). Cochrane Database Syst Rev. 2010;1:1-138.

18. Unterscheider J, Daly S, Geary MP, Kennelly MM, McAuliffe FM, O'Donoghue K, et al. Optimizing the definition of intrauterine growth restriction: the multicenter prospective PORTO Study. Am J Obstet Gynecol. 2013;208(4):290.e1-6.

19. Morales-Roselló J, Khalil A, Morlando M, Papageorghiou A, Bhide A, Thilaganathan B. Changes in fetal Doppler indices as a marker of failure to reach growth potential at term. Ultrasound Obstet Gynecol. 2014;43(3):303-10.

20. Unterscheider J, Daly S, Geary MP, Kennelly MM, McAuliffe FM, Keelin O, et al. Definition and management of fetal growth restriction: a survey of contemporary attitudes. Eur J Obstet Gynecol Reprod Biol. 2014;174:41-5. 
21. Papageorghiou AT, Ohuma EO, Altman DG, Todros T, Ismail LC, Lambert A, et al. International standards for fetal growth based on serial ultrasound measurements: the Fetal Growth Longitudinal Study of the INTERGROWTH21 st Project. Lancet. 2014;384(9946):869-79.

22. Brodszki J, Marsál K. Management of pregnancies with suspected intrauterine growth retardation in Sweden. Acta Obstet Gynecol Scand. 2000;79(9):723-8.

23. Savchev S, Figueras F, Gratacos E. Survey on the current trends in managing intrauterine growth restriction. Fetal Diagn Ther. 2014;36(2):129-35.

24. Henrichs J, Verfaille V, Viester L, Westerneng M, Molewijk B, Franx A, et al. Effectiveness and cost-effectiveness of routine third trimester ultrasound screening for intrauterine growth restriction: study protocol of a nationwide stepped wedge cluster-randomized trial in The Netherlands (The IRIS Study). BMC Pregnancy and Childbirth. 2016;16:310.

25. Nederlandse Vereniging voor Obstetrie en Gynaecologie. Kwaliteitsnorm geavanceerd ultrageluidonderzoek. NVOG. 1997. http://nvog-documenten.nl/index.php?pagina=/richtlijn/item/pagina. php\&richtlijn_id=873. Accessed 1 Oct 2014

26. Lees C, Marlow N, Arabin B, Bilardo CM, Brezinka C, Derks JB, et al. Perinatal morbidity and mortality in early-onset fetal growth restriction: cohort outcomes of the trial of randomized umbilical and fetal flow in Europe (TRUFFLE). Ultrasound Obstet Gynecol. 2013;42(4):400-8.

27. Salomon $\sqcup$, Alfirevic Z, Berghella V, Bilardo C, Hernandez-Andrade E, Johnsen $\mathrm{SL}$, et al. Practice guidelines for performance of the routine mid-trimester fetal ultrasound scan. Ultrasound Obstet Gynecol. 2011;37(1):116-26.

28. Snijders RJM, Thom EA, Zachary JM, Platt LD, Greene N, Jackson LG, et al. First-trimester trisomy screening: nuchal translucency measurement training and quality assurance to correct and unify technique. Ultrasound Obstet Gynecol. 2002;19(4):353-9.

29. Dudley NJ, Chapman E. The importance of quality management in fetal measurement. Ultrasound Obstet Gynecol. 2002;19(2):190-6.

30. Salomon LJ, Ville Y. Quality control of prenatal ultrasound. Ultrasound Rev Obstet Gynecol. 2005;5(4):297-303.

31. Scioscia M, Vimercati A, Ceci O, Vicino M, Selvaggi LE. Estimation of birth weight by two-dimensional ultrasonography: a critical appraisal of its accuracy. Obstet Gynecol 2008;111(1):57-65.

32. Ville Y. Ceci n'est pas une échographie': a plea for quality assessment in prenatal ultrasound. Ultrasound Obstet Gynecol. 2008;31(1):1-5.

33. Salomon $L$, Ville $Y$. The science and art of quality in obstetric ultrasound. Curr Opin Obstet Gynecol. 2009;21(2):153-60.

34. Maulik D, Yarlagadda P, Youngblood JP, Ciston P. Comparative efficacy of umbilical arterial Doppler indices for predicting adverse perinatal outcome. Am J Obstet Gynecol. 1991;164(6):1434-40.

35. Alberry M, Soothill P. Management of fetal growth restriction. Arch Dis Child Fetal Neonatal Ed. 2007;92(1):F62-7.

36. van Wyk $L$, Boers KE, van der Post JA, van Pampus MG, van Wassenaer AG, van Baar AL, et al. Effects on (neuro) developmental and behavioral outcome at 2 years of age of induced labor compared with expectant management in intrauterine growth-restricted infants: long-term outcomes of the DIGITAT trial. Am J Obstet Gynecol. 2012;206(5):406-e1.

37. Boers KE, Vijgen SMC, Bijlenga D, van der Post JAM, Bekedam DJ, Kwee A, et al. Induction versus expectant monitoring for intrauterine growth restriction at term: randomised equivalence trial (DIGITAT). BMJ. 2010;341

38. Diamond IR, Grant RC, Feldman BM, Pencharz PB, Ling SC, Moore AM, et al. Defining consensus: a systematic review recommends methodologic criteria for reporting of Delphi studies. J Clin Epidemiol. 2014;67(4):401-9.

39. Goodman CM. The Delphi technique: a critique. J Adv Nurs. 1987;12(6):729-34.

40. Keeney S, Hasson F, McKenna HP. A critical review of the Delphi technique as a research methodology for nursing. Int J Nurs Stud. 2001;38(2):195-200.

41. Sumsion T. The Delphi technique: an adaptive research tool. Br J Occup Ther. 1998;61(4):153-6.

42. Grol R. Successes and failures in the implementation of evidence-based guidelines for clinical practice. Med Care. 2001;39(8):II-46-54.

43. Kinsman L, James E, Ham J. An Interdisciplinary, Evidence-Based Process of Clinical Pathway Implementation Increases Pathway Usage. Prof Case Manag. 2004;9(4):184-96.

44. Fleuren $M$, Wiefferink $K$, Paulussen $T$. Determinants of innovation within health care organizations. Int J Qual Health Care. 2004;16(2):107-23.

45. McKenna HP. The Delphi technique: a worthwhile research approach for nursing? J Adv Nurs. 1994;19(6):1221-5.

46. Hasson F, Keeney S, McKenna H. Research guidelines for the Delphi survey technique. J Adv Nurs. 2000;32(4):1008-15.

\section{Submit your next manuscript to BioMed Central and we will help you at every step:}

- We accept pre-submission inquiries

- Our selector tool helps you to find the most relevant journal

- We provide round the clock customer support

- Convenient online submission

- Thorough peer review

- Inclusion in PubMed and all major indexing services

- Maximum visibility for your research

Submit your manuscript at www.biomedcentral.com/submit 